\title{
Laser lithotripsy using dusting technique (low energy, high frequency) for symptomatic upper urinary tract stones
}

\author{
A. Ashmawy ${ }^{1}$, M. Khedr², I. R. Saad' , S. Zamel ${ }^{1}$ and A. Kassem ${ }^{\text {1* }}$
}

\begin{abstract}
Background: A prospective study to assess the feasibility of stone dusting technique (low energy and high frequency) during laser lithotripsy in symptomatic upper urinary tract |(UUT) stones.

Methods: Sixty patients with symptomatic single or multiple UUT stones less than $3 \mathrm{~cm}$ in diameter were included. Patients with coagulation disorders and active UTIs were excluded. All patients were clinically evaluated and underwent non-contrast spiral CT (NCSCT) to detect stone site, size, number, Hounsfield unit. A rigid or flexible ureteroscope was used with stone dusting using the Ho: YAG laser at low-energy and high-frequency $(0.5 \mathrm{~J} \& 20 \mathrm{~Hz})$ set. Operative and fluoroscopy time, total energy delivered, type of stent, hospitalization time, complications and its grade, and stone-free rate using NCSCT after 4 weeks were recorded.

Results: The mean stone size \pm SD (range) was $1.55 \pm 0.55(0.5-3) \mathrm{cm}$; out of sixty patients (50 with single stone and 10 with multiple stones), fifty-five patients were stone-free at 4 weeks. Complications had occurred in 11 patients (eight with grade I, one with grade II, and two with grade IIla) according to Clavien-Dindo grading of surgical complications. Stone size was the only parameter which correlated significantly with stone-free rate. No significant correlation was found between incidence of complications and other parameters (stone size, site, BMI, age and operative time).
\end{abstract}

Conclusions: Stone dusting technique is feasible, safe and effective in management of UUT stones.

Keywords: Stone dusting, Lithotripsy, Laser

\section{Background}

Ureterorenoscope is a less invasive modality for treatment of ureteric and renal stones. It may be used antegrade or retrograde [1].

Laser settings or techniques are an important issue of research as with increased pulse energy many disadvantages appear. Till now, there is no clear recommendation on the best mode of laser lithotripsy either fragmentation or dusting.
Stone dusting is to convert stone to tiny fragments or dust by decreasing energy and varying frequency to allow these tiny fragments to pass spontaneously. Laser fibers are damaged with energy $>1 \mathrm{~J}$ due to thermal effect $[2,3]$. Fragment size is a challenging problem to urologists as it correlates with or affects stone-free rates (SFRs), as small fragment size results in high SFRs $[4,5]$. Stone retropulsion or migration increases with high energy.

Several studies were done using different laser settings. But all suggest that energy $<1 \mathrm{~J}$ results in small fragment size, decreases migration, and decreases laser fiber damage [2].

The aim of the current study is to assess the safety and efficacy of stone dusting technique (low energy and high

*Correspondence: Dr_ayman_kasem@yahoo.com

1 Urology Department, Cairo University, Cairo, Egypt

Full list of author information is available at the end of the article 
frequency) during laser lithotripsy in symptomatic UUT (upper urinary tract) stones.

\section{Methods}

This is a prospective study aiming at the assessment of safety and efficacy of ureteroscopy (URS) and laser lithotripsy (LL) with dusting technique (low energy high frequency) in the management of upper urinary tract stones in sixty patients done at The Urology Department, during the period between July 2017 and February 2018. (Hospital name is blinded for peer review.)

Symptomatic single or multiple UUT stones (mid- and upper ureter, pelvic and calyceal stones), less than $3 \mathrm{~cm}$ in maximum diameter in both genders, were included with exclusion of stone size $>3 \mathrm{~cm}$, coagulation disorders, and active UTIs. All patients were evaluated by history taking, physical examination, history of previous stone disease, and associated medical diseases. Patient physical status (PS) was categorized according to American Society of Anesthesiologists.

Mid-stream urine analysis, urine culture, serum creatinine, $\mathrm{CBC}$, coagulation profile, and serum electrolyte were done.

All patients underwent non-contrast spiral CT (NCSCT) to detect stone site, size, number, hounsfield unit (HFU), and degree of hydroureteronephrosis (HUN).

The semirigid long ureteroscope made by Karl Storz (Tuttlingen, Germany) with size of $12 \mathrm{Fr}$, length of $43 \mathrm{~cm}$, distal tip of $9 \mathrm{Fr}$, 6-degree lens, and $6 \mathrm{Fr}$, central channel was used.

Flex $-\times 2$ flexible ureteroscope made by Karl Storz (Tuttlingen, Germany) is $7.5 \mathrm{Fr}$ in mid shaft, $6.7 \mathrm{Fr}$ at tip, $65 \mathrm{~cm}$ in length, and 3.6 Fr working channel. Field of view is 90 -degree.

Laser (LISA laser products-OHG, Katzenberg, landau, Germany). The generator had the following specifications: fiber rate $5-20 \mathrm{~Hz}$, power $30-\mathrm{W}$, energy $0.5-2.7 \mathrm{~J}$, and wavelength 2.1 micron.

The Laser fiber used was Flexi Fib with an optical core diameter 272 micron, an outer diameter 420 microns and main bend radius $15 \mathrm{~mm}$ made by LISA Laser product (Katzenberg, landau, Germany).

Surgical procedure:

- Patients with infected urine were treated preoperatively by the appropriate antibiotics according to urine culture and sensitivity. Prophylactic parenteral antibiotics were given with induction of anesthesia in the form of 3rd-generation cephalosporin. Antibiotic treatment was usually continued during the first $24 \mathrm{~h}$ postoperatively.

- Patients were then maintained on oral antibiotics for 5 days postoperatively.
- Patients were placed in the dorsal lithotomy position with abducted contralateral leg under general or spinal anesthesia.

Under fluoroscopic monitoring, a guidewire was placed till the kidney; the lower ureter was dilated using sequential Teflon dilators. A ureteral access sheath was used to facilitate easy passage of flexible ureteroscope. The ureteroscope was then introduced alongside the guide wire until the stone was seen; if flexible URS is planned, it is passed carefully over a second guidewire under fluoroscopic imaging. Stone dusting is done using the Ho: YAG laser that is set to low energy and high frequency $(0.5 \mathrm{~J}$ $\& 20 \mathrm{~Hz}$ ). After completion of stone fragmentation, the ureter was inspected for any evidence of trauma. A ureteric catheter was inserted at the end of the procedure for a period of $24 \mathrm{~h}$. If ureteric injury was suspected or residual stones, a DJ stent was placed to be removed after 4 weeks.

Postoperative care and follow-up:

- Patients were observed for $24 \mathrm{~h}$ postoperatively for loin or abdominal pain, fever, or hematuria. Analgesics (NSAIDs) and/or narcotics were given. Patients with renal impairment were discharged after laboratory and clinical stabilization. On the next day, the ureteric catheter was removed, and antibiotic treatment was continued for 5 days after discharge.

- Postoperative complications were classified according to Clavien-Dindo grading of surgical complications (Dindo et al., 2004). Operative and fluoroscopy time in minutes, endoscopy utilized, total energy delivered, type of stent, hospitalization time in days, complications and their grade, and stone-free status as recorded by NCSCT after 4 weeks were reported. Patients were defined as stone-free if there is no evidence of residual fragments $>4 \mathrm{~mm}$ in size [6].

\section{Results}

Sixty patients were included in this study to evaluate the safety and efficacy of URS and LL using stone dusting technique (low energy-high frequency) for upper urinary tract stones. This study was conducted at The Urology Department, from July 2017 to February 2018.

Baseline characteristics of included patients are shown in Table $1.71 .6 \%$ of stones were ureteric in position, and $83.3 \%$ of patients had single stone.

Mean operative time was $58.5 \mathrm{~min}$. DJ was inserted in $63.3 \%$ of patients. Other operative details are shown in Table 2.

Stone-free rate was $91.66 \%$ for primary procedure. 
Table 1 Baseline patients characteristics

\begin{tabular}{|c|c|}
\hline \multicolumn{2}{|l|}{ Total patients $n=60$} \\
\hline Mean age $\pm S D$ (range) & $50.50 \pm 13.87(22-79)$ years \\
\hline \multicolumn{2}{|l|}{ Gender } \\
\hline Male; number (\%) & $20(33.33)$ \\
\hline Female; number (\%) & $40(66.67)$ \\
\hline Mean $\mathrm{BMI} \pm \mathrm{SD}$ (range) & $28.21 \pm 3.84(20-35)$ \\
\hline \multicolumn{2}{|l|}{ ASA score } \\
\hline l; number (\%) & $28(46.67)$ \\
\hline II; number (\%) & $32(53.33)$ \\
\hline History of previous surgery; number (\%) & $15(25 \%)$ \\
\hline \multicolumn{2}{|l|}{ Degree of HUN; number (\%) } \\
\hline Mild & $29(48.33)$ \\
\hline Moderate & $26(43.33)$ \\
\hline Severe & $5(8.33)$ \\
\hline \multicolumn{2}{|l|}{ Site of the stone; number (\%) } \\
\hline Ureter & $43(71.67)$ \\
\hline Pelvic & $10(16.67)$ \\
\hline Calyceal & $2(3.33)$ \\
\hline Pelvicalyceal & $5(8.33)$ \\
\hline \multicolumn{2}{|l|}{ Number of stones; number (\%) } \\
\hline Single & $50(83.33)$ \\
\hline Multiple & $10(16.67)$ \\
\hline Mean stone size $\pm S D$ (range) in $\mathrm{cm}$ & $1.55 \pm 0.55(0.5-3)$ \\
\hline Mean HFU \pm SD (range) & $794.22 \pm 296.63(290-1800)$ \\
\hline Mean creatinine level \pm SD (range) & $1.38 \pm 1.39(0.5-7)$ \\
\hline
\end{tabular}

Table 2 Intraoperative parameters

\begin{tabular}{ll}
\hline $\begin{array}{l}\text { Total patients } n=60 \\
\text { Mean operative time in min } \pm \text { SD } \\
\text { (range) }\end{array}$ & $58.50 \pm 16.21(30-100)$ \\
$\begin{array}{l}\text { Mean fluoroscopy time in min } \pm \text { SD } \\
\text { (range) }\end{array}$ & $8.45 \pm 2.98(3-15)$ \\
$\begin{array}{l}\text { Endoscopy utilized; number (\%) } \\
\quad \text { Semirigid }\end{array}$ & $43(71.6)$ \\
$\quad$ Flexible & $10(16.7)$ \\
$\quad$ Both & $7(11.7)$ \\
$\begin{array}{l}\text { Mean total energy delivered in J } \pm S D \\
\text { (range) }\end{array}$ & $6836.23 \pm 3018.00(1002-19,314)$ \\
Stenting; number (\%) & \\
$\quad$ DJ & $38(63.33 \%)$ \\
$\quad$ Ureteric catheter & $22(36.67 \%)$
\end{tabular}

Single stone was present in 50 patients with 48 patients (96\%) being stone-free after primary procedure.

Ten patients had multiple stones with only 7 patients (70\%) were free after primary procedure, and the difference was statistically significant.

Complications occurred in 11 patients (18.33\%). (Eight cases with fever controlled by antipyretics, one
Table 3 Postoperative data

\begin{tabular}{ll}
\hline Total patients $n=60$ & \\
Mean hospitalization time in days \pm SD (range) & $4.12 \pm 2.43(2-19)$ \\
Complications; number (\%) & $11(18.33 \%)$ \\
Grade of complication $n=11$ & \\
$\quad$ Grade I (\%) & $8 / 11(73)$ \\
$\quad$ Grade II (\%) & $1 / 11(9)$ \\
$\quad$ Grade IIla (\%) & $2 / 11(18)$ \\
Stone-free rate (for single session) number (\%) & $55(91.67)$ \\
Number of sessions; number (\%) & \\
$\quad$ Single & $55(91.67)$ \\
$\quad$ Multiple & $5(8.33)$ \\
\hline
\end{tabular}

Table 4 Comparison between baseline parameters with stonefree rate

\begin{tabular}{lllr}
\hline $\begin{array}{l}\text { Baseline and } \\
\text { operative } \\
\text { parameters }\end{array}$ & $\begin{array}{l}\text { Outcome parameters } \\
\text { Stone-free rate }\end{array}$ & p value \\
\cline { 2 - 3 } & Yes $(\mathbf{n}=\mathbf{5 5})$ & No $(\mathbf{n}=\mathbf{5})$ & \\
\hline Stone size & $1.48 \pm 0.45$ & $2.34 \pm 0.90$ & $<0.001$ \\
HFU & $790.71 \pm 300.30$ & $832.80 \pm 280.03$ & 0.764 \\
Stone number & & & \\
$\quad$ Single & $48 / 50(96 \%)$ & $2 / 50(4 \%)$ & 0.007 \\
$\quad$ Multiple & $7 / 10(70 \%)$ & $3 / 10(30 \%)$ & \\
\hline
\end{tabular}

patient with pyelonephritis treated by antibiotic regimen other than that approved by hospital policy for chemoprophylaxis, and two patients necessitate postoperative double J ureteric stent. Other postoperative data are shown in Table 3.

Comparison between baseline and operative parameters with the outcome data (stone-free rate and complication rate) revealed that stone size and number significantly correlated with stone-free rate, while no significant correlation was found between stone site, size, operative time, and incidence of complications (Tables 4 and 5). Operative time correlated significantly with stone size, site and HFU (Table 6). Long operative time and large stone size necessitated double J internal stent rather than ureteric catheter (Table 7). Thirtyeight patients $(63.3 \%)$ received a DJ stent; Of them, $10.5 \%$ had bilateral stones, $26.3 \%$ had residual fragments, $7.9 \%$ needed multiple sessions, $2.6 \%$ had solitary kidney, $39.4 \%$ had infection, and $13.3 \%$ had ureteric wall injury.

The relation between stone size, $\mathrm{HU}$ and total laser energy delivered was statistically significant (total energy delivered increased with the increase in stone size and $\mathrm{HU}$ ) (Table 8). 
Table 5 Comparison between baseline patient characteristics, operative parameters and complication rate

\begin{tabular}{|c|c|c|c|}
\hline & \multicolumn{2}{|l|}{ Complications } & \multirow[t]{2}{*}{$p$ value } \\
\hline & Yes $n=11(18.33 \%)$ & No $n=49(81.67 \%)$ & \\
\hline $\mathrm{BMI} \pm \mathrm{SD}$ & $28.05 \pm 4.32$ & $28.24 \pm 3.77$ & 0.886 \\
\hline ASA score & & & 0.562 \\
\hline I $(n=28)$ & 6/28 (21.4\%) & $22 / 28(78.6 \%)$ & \\
\hline$\|(n=32)$ & 5/32 (15.6\%) & $27 / 32(84.4 \%)$ & \\
\hline Stone size \pm SD & $1.71 \pm 0.49$ & $1.52 \pm 0.56$ & 0.295 \\
\hline Site & & & 0.324 \\
\hline Ureter $(n=43)$ & $6 / 43(14 \%)$ & $37 / 43(86 \%)$ & \\
\hline Pelvic $(n=10)$ & $3 / 10(30 \%)$ & $7 / 10(70 \%)$ & \\
\hline Calyceal $(n=2)$ & $0 / 2(0 \%)$ & $2 / 2(100 \%)$ & \\
\hline Pelvicalyceal $(n=5)$ & $2 / 5(40 \%)$ & $3 / 5(60 \%)$ & \\
\hline Op. time $\pm S D$ & $63.00 \pm 17.86$ & $57.49 \pm 15.84$ & 0.312 \\
\hline Stent type & & & 0.503 \\
\hline$J J$ stent $(n=38)$ & 6/38 (15.8\%) & $32 / 38(84.2 \%)$ & \\
\hline Ureteric catheter $(n=22)$ & $5 / 22(22.7 \%)$ & $17 / 22(77.3 \%)$ & \\
\hline
\end{tabular}

Table 6 Comparison between operative time and stone size, site, HFU

\begin{tabular}{lll}
\hline Patient number (60) & Mean operative time in $\min \pm$ SD (range) & $\boldsymbol{p}$ value \\
\hline Site of stone & Ureteric; $n=34(72 \%)$ & $53.41 \pm 12.08(30-85)$ \\
& Pelvic $n=10(17 \%)$ & $66.8 \pm 14.9(40-90)$ \\
& Calyceal $n=2(3 \%)$ & $55 \pm 14.1(45-65)$ \\
& Pelvicalyceal $n=5(8 \%)$ & $87 \pm 17.9(65-100)$ \\
HFU & $<400 ; n=5(8.33 \%)$ & $57.00 \pm 10.36(45-70)$ \\
& $400-800 ; n=23(38.33 \%)$ & $56.39 \pm 16.30(40-100)$ \\
Stone size & $>800 ; n=32(53.33 \%)$ & $60.25 \pm 17.05(30-100)$ \\
& $<1 \mathrm{~cm} \mathrm{n}=9(15 \%)$ & $41.67 \pm 9.68(30-60)$ \\
& $1-2 \mathrm{~cm} \mathrm{n}=44(73.3 \%)$ & $59.77 \pm 12.28(40-90)$ \\
\hline
\end{tabular}

Table 7 Parameters affecting type of stent at the end of the procedure

\begin{tabular}{|c|c|c|c|}
\hline & \multicolumn{2}{|l|}{ Stent type } & \multirow[t]{2}{*}{$p$ value } \\
\hline & $\begin{array}{l}J \text { J stent } \\
n=38\end{array}$ & $\begin{array}{l}\text { Ureteric cath } \\
\mathrm{n}=22\end{array}$ & \\
\hline Stone size & $1.77 \pm 0.45$ & $1.17 \pm 0.48$ & $<0.01$ \\
\hline Stone site & & & 0.778 \\
\hline Ureter $n=43$ & $26 / 43(60.47 \%)$ & 17/43 (39.53\%) & \\
\hline Pelvic $n=10$ & $7 / 10(70 \%)$ & $3 / 10(30 \%)$ & \\
\hline Calyceal $n=2$ & $1 / 2(50 \%)$ & $1 / 2(50 \%)$ & \\
\hline Pelvicalyceal $n=5$ & $4 / 5(80 \%)$ & $1 / 5(20 \%)$ & \\
\hline Operative time & $62.71 \pm 15.25$ & $51.22 \pm 15.51$ & $<0.01$ \\
\hline
\end{tabular}

Table 8 Total energy delivered vs. stone size and HFU

\begin{tabular}{lll}
\hline Variable & Total energy delivered & $\boldsymbol{p}$ value \\
\hline Stone size $1.55 \pm 0.55$ & $6836.23 \pm 3018.00$ & 0.001 \\
HFU 794.22 \pm 296.63 & $6836.23 \pm 3018.00$ & 0.009 \\
\hline
\end{tabular}




\section{Discussion}

Laser settings or techniques are becoming important point of research. Stone dusting is a technique whereby a stone is converted to tiny fragments or dust by decreasing energy and varying frequency (low energy $0.2-1 \mathrm{~J}$, and high frequency $15-80 \mathrm{~Hz}$ ). Studies suggested that decreasing pulse energy to less than $1 \mathrm{~J}$ might result in small fragment size, less stone migration, decreasing laser fiber damage and decreasing complication, especially ureteric wall injury or perforation [2].

The current study is a prospective case series aimed at the evaluation of the safety and efficacy of ureteroscopy (URS) and laser lithotripsy (LL) using stone dusting technique (low energy-high frequency) for management of UUT stones.

Our results reveal that stone-free rate (SFR) was $91.66 \%$. Complications occurred in $18.33 \%$ of patients, most of them were of grade I (73\%).

This stone-free rate is much higher than that observed by Ben et al. 2015 [7] who reported a SFR of $60.9 \%$ in dusting group and $89.9 \%$ in basketing group, it is noteworthy that Ben et al. defined stone-free as no fragments at all in US or KUB, while stone-free in our study was defined if there is no evidence of residual fragments $>4 \mathrm{~mm}$ in size. On the other side, [7] reported lower complication rate in the dusting group (8.69\%) compared to our rate.

SFR in the current study is also higher than that reported by Wael et al. [8] both in the dusting group $(86 \%)$ and in the fragmentation group (89\%) in his study.

Mean operative time in the current study was $(58.50 \pm 16.21 \mathrm{~min})$ which is longer than that observed by [7] who reported mean operative time of $(40.50 \pm 14.70 \mathrm{~min})$ in dusting group, and also longer than that observed by Wael et al. (2015) who compared stone dusting with stone fragmentation in 46 patients (23 in each group) for $2 \mathrm{~cm}$ single renal stones using flexible ureteroscopy. This may be related to larger mean stone size in our study compared to theirs. Additionally, they included patients with single stones only, while in the current study we included patients with single or multiple stones.

In our study, we reported long hospital stay (because we had one patient with sepsis, and she had long hospital stay (19 days), also we had 1-2 days preoperative hospital stay).

We tried to find a relation between different parameters (stone site, size, HFU) and its effect on the outcome (stone-free rate, complications) and our results revealed that stone-free rate correlated significantly with stone size, while no significant correlation had been found between stone site, size, operative time and incidence of complications. Operative time correlated significantly with stone size, site and HFU.

Our results are in agreement with Rana and Ather [9] as they found that HFU and stone diameter were significant predictors of TLE (total laser energy) and TLT (total laser time) when using Ho:YAG laser for stone fragmentation.

In the current study, long operative time and large stone size necessitated double J internal stent rather than ureteric catheter.

Although our study is a prospective one with outcome comparable to other study, we think that comparison data give better preoperative counseling to patients and health facilities regarding anticipated hospital course, length of hospital stay, cost, and need for internal stent.

The main limitation of our study is being a non-comparative study with small sample size.

\section{Conclusions}

Based on the results of the current study, we can conclude that stone dusting technique is feasible, safe, and effective in management of UUT stones.

\section{Abbreviations}

UUT: Upper urinary tract; NCSCT: Non-contrast spiral CT; HFU: Hounsfield unit; BMI: Body mass index; LL: Laser lithotripsy; URS: Ureteroscopy; SFRs: Stone-free rates; DJ: Double J stent; HUN: Hydroureteronephrosis.

\section{Acknowledgements}

No agency to be acknowledged. We acknowledge our patients who suffer a lot and hope this work improve their quality of life.

\section{Authors' contributions}

All authors have read and approved the manuscript, and all authors contributed to the work. AK: revision of the work and writing of the manuscript; AA: supervision of the work and operative work; MK: data collection and writing; IR: idea of the work and supervision of operative work; SZ: idea of the work and supervision of manuscript writing. All authors have read and approved the manuscript.

\section{Funding}

No funding agent

\section{Availability of data and materials}

The datasets used and/or analyzed during the current study are available from the corresponding author on reasonable request.

\section{Declarations}

Ethics approval and consent to participate

All patients signed informed consent. The study was carried out following the Helsinki Declaration and was approved by the local ethical committee of the urology department, kasr Alainy hospital, Cairo University, as a master thesis; hence, it did not have an ethics committee's reference number. 


\section{Consent for publication}

Patients had signed informed consent for use of their data in research and publication without the appearance of their names.

\section{Competing interests}

The authors declare that they have no competing interests.

\section{Author details}

${ }^{1}$ Urology Department, Cairo University, Cairo, Egypt. ${ }^{2}$ Urology Department, Maadi Military Hospital, Cairo, Egypt.

Received: 5 May 2021 Accepted: 16 November 2021

Published online: 04 December 2021

\section{References}

1. Troy A, Anagnostou T, Tolley D (2004) Flexible upper tract endoscopy. BJU Int 93(5):671-679

2. Vassar G, Chan K, Teichman J et al (1999) Ho: YAG lithotripsy photothermal mechanism. J Endourol 13(3):181-190

3. Spore S, Prabakharan S, Teichman J et al (1999) Proteus mirabilis viability after lithotripsy of struvite calculi. J Urol 162(5):1666-1669

4. Sea J, Jonat L, Chew B et al (2012) Optimal power settings for Holmium: YAG lithotripsy. J Urol 187(3):914-919

5. Chawla S, Chang M, Chang A et al (2008) Effectiveness of high-frequency Ho: YAG laser stone fragmentation the "popcorn effect." J Endourol 22(4):645-650

6. Acar C, Cal C (2012) Impact of residual fragments following endourological treatments in renal stones. Adv Urol 2012(5):813523

7. Ben H, Ojas S, Roger L et al (2015) Dusting VS basketing during ureteroscopic lithotripsy-what is more effective. J Urol 193(1):347-348

8. Wael G, Ahmed M (2015) flexible URS holmium laser stone dusting VS fragmentation for $2 \mathrm{~cm}$ single renal stone. J Urol 193(4):312-313

9. Rana R, Ather M (2020) Hounsfield units-a significant predictor of lasering time and energy in the management of upper urinary tract stones using Holmium: Yttrium-Aluminum Garnet lasers. Int Urol Nephrol 52(9):16371641. https://doi.org/10.1007/s11255-020-02442-w

\section{Publisher's Note}

Springer Nature remains neutral with regard to jurisdictional claims in published maps and institutional affiliations.

\section{Submit your manuscript to a SpringerOpen ${ }^{\circ}$ journal and benefit from:}

- Convenient online submission

- Rigorous peer review

- Open access: articles freely available online

- High visibility within the field

- Retaining the copyright to your article 